\title{
An Educational Programme of Sanitation in India: A Mirage to Reality
}

\author{
Aafreen Naz ${ }^{1}$ and S. M. Jawed Akhtar ${ }^{2}$ \\ ${ }^{1}$ Research Scholar, ${ }^{2}$ Professor \\ ${ }^{1 \& 2}$ Department of Economics, Aligarh Muslim University, Uttar Pradesh, India \\ E-Mail: aafreennazamu@gmail.com
}

\begin{abstract}
Sanitation is the need of the present era. It is the basis of disease free, clean environment and healthy aspect of a hygienic and decent life style. According to the World Bank data the 2.3 billion people in the world live without an access to a toilet and almost 892 million people practice open defecation. Only $69 \%$ of world's population have an access to toilets and $38 \%$ have managed to go for safe and germs free defecation. It represents a high categorical underprivileged section of a society deprived of basic amenities. The Indian Ministry of Statistics and Programme implementation (MOPS) in its published 2016 report says that usage of toilet is 95.6 percent in rural region and $\mathbf{9 8 . 8}$ percent in urban areas which shows a considerable level of hygienic defecation process practices in Indian households. India has implemented Swacha Bharat Abhiyan (SBA) or Swacha Bharat Mission (SBM) with an objective of cleanliness drive and making India open defecation free. An NSSO survey reveals that 42.5 percent people in rural areas and 87.9 percent in urban areas have access to water facility in toilets. An educational drive or a comprehensive programme is implemented in India with wider application and coverage.
\end{abstract}

Keywords: Education, Sanitation and Application

\section{INTRODUCTION}

The education system must be the one which produced the best version of a person in the due course of study. It is the best way to acclimatize the young minds and transform them into a responsible and dutiful citizen of the country. Sanitation is a comprehensive and inclusive process that includes cleanliness, effective waste management, final disposal of industrial waste, management of nonbiodegradable material etc. The burning issue started with the very inception of the ideologies of the father of nation. At the very beginning he asserts the importance its social long term effects. Mahatma Gandhi was in the favour of imparting such an education which collectifies the thoughts and sensitive's the minds towards less privileged masses. Apart from education he gave special concerns to sanitation and cleanliness among the social classes irrespective of caste. According to him "Sanitation is much more important than political freedom". On this line the Prime Minister of India Narendra Modi recognised the importance of sanitation and launched a scheme Swacha Bharat Abhiyan under the foray of a mission or campaign started for the period 2014 to 2017.The retarded and dominantly forgotten vision is revived in a time bound manner. The objective of Swacha Bharat Abhiyan is to make India open defecation free by building a concrete and functional toilet in each household and making them responsible. The ancient practise and taboo of defecating in open places is addressed at a quite massive scale. The mission was launched by PM Narendra Modi on $2^{\text {nd }}$ October 2014 with an edifice to make India clean and solid waste free. The following objectives are made to achieve till the end of the period 2019. These are as follows.

1. To build 1.04 crore individual household toilet

2. To construct 2.52 lakh community toilets seats

3. To prepare 2.56 lakh public toilets

4. To maintain end to end solid management in all 4041 urban local bodies, behavioural change towards sanitation and cleanliness.

The programme is divided into Swacha Bharat Abhiyan (Rural) and Swacha Bharat Abhiyan (Urban). The basic structure that to be constructed under this programmes are Individual Household Latrines (IHHL), Community Sanitary Complex, Institutional toilets; solid and liquid waste management and information, education and communication activities. The scheme is bound to cover all the marginalised communities including Below Poverty Line (BPL) and Above Poverty Line (APL) households, Scheduled Caste/Tribe communities, households with handicap house lady, landless farmers, labourers and marginalised and deprived farmers. The IHHL are also partially funded under Mahatma Gandhi National Rural Employment Guarantee Scheme (MGNREGA) scheme which is also paving a lot of effort to increase the progress rate of the Swacha Bharat Abhiyan (SBM). Later in 2014 the MGNREGA was delinked with toilet construction due to inefficient machinery. The government is working bit by bit to reduce the gridlocks of the unhygienic system of Indian society not only affecting the health of the people but also making financial loss to the economy in terms of labour hours and reduced efficiency.

\section{REVIEW OF LITERATURE}

Isunju, Schwartz, Schouten, Johnson and Dijk (2011) in their study analyses the situation of sanitation in the slum areas and the significant impact of lack of sanitation facilities on health of slum dwellers. The research recognises the factors such as less priority to sanitation, lack of funds, slow improvement mechanism and lack of appropriate technical solutions behind the slow process of sanitation. The Millennium Development Goals are highlighted in respect of sanitation. The paper says that 
sanitation is having many other factors except health that signifies its importance in human life. The tenant's inability to pay negatively affects the demand for better sanitation facilities in slums by discouraging the landlords to work in this regard. Although, political agendas are for the better public facilities but some overhauls still exists. In slum areas, community toilets are prevalent but the monitoring and management of such public good is hard to maintain. Thus, it reduces the drives and impulses for further sanitation and health related programmes at the stage of implementation and administration.

Minakshi P Hazarika (2015) examines the state of sanitation in Jorhat district of Assam. It is based on the primary survey conducted in the rural area, slum of an urban area and a tea garden area. The study reveals that the region needs a lot of government attention to enhance the level of sanitation. Women and children are suffering the most as the duty of women is to fetch water and serve the family. Children are very prone to diseases in case of open defecation. By imparting awareness about cleanliness and its benefits can help a lot to improve the current scenario. It highlights the role of Total Sanitation Campaign launched in 1991 that the improvement is quite remarkable but the whole process is slow and cumbersome.

Swain and Pathela (2016) examined the situation of sanitation and hygeine. The paper elaborated the existing condition. It has concluded that approximately three-fourth people are not aware about the popular programme of Swacha Bharat Abhiyan in the survey conducted in two selected districts such as Ghaziabad (Uttar Pradesh) and Jabalpur (Madhya Pradesh).This study is basically focussed on the deprived areas which are lacking in basic sanitation facilities and pointed out the areas where the sanitation need is much higher than the rest of the country.

Ohmu and Augusomu (2018) examine the current status of Water, Sanitation and Hygiene (WASH) in Sub-Saharan African countries. It is basically a review of WASH services provided by the government which are necessary for promoting good health and socio-economic development. The condition in sub-Saharan African is worse than the rest of the world. The Millennium Development Goal of sanitation is performing indigently over a stretch of time. It shows that adequate strategies are needed by every county of the specified region to tackle the problem of sanitation and health related issues as highly prevalent in that area. However, any particular strategy is not applicable to resolve all the problems, each area require a different and relevant solution such as political will.

\section{OBJECTIVES OF THE STUDY}

The main objectives of this study are as follows

1. To analyze the current situation of sanitation and hygiene in India.
2. To assess the extent and success of Swacha Bharat Abhiyan.

3. To evaluate the number of IHHL, School and Anganwadi toilets constructed over a period of time.

\section{SOURCES OF DATA AND METHODOLOGY}

The study is based on the secondary data available from the Ministry of Drinking Water and Sanitation, Government of India. The data is also collected from the reports of Ministry of Human Resource Development (MHRD) of various years. The data of given years is collected, organized and presented in a systematic and tabulated form. The results are analyzed and considered through the mathematical approach. The data is also collected from the annual report of Swachta Status Report of 2016-17.

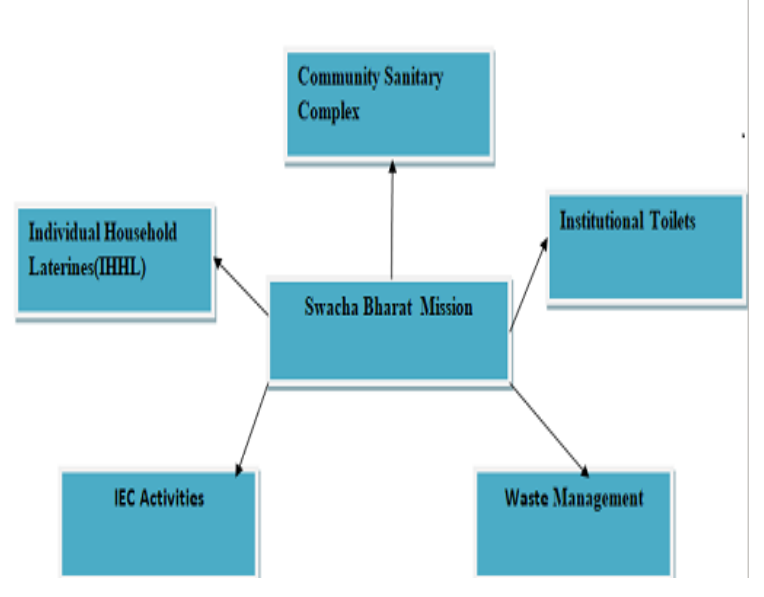

Fig.1 Components of Swacha Bharat Mission

Community Sanitary complexes are made at every gram pachayat at a specified location of public gathering where the facility is optimised fully. Sanitation is the most important process which affect children the most. Institutional toilets are built considering the need and its adverse effect on kids in case of its absense. A number of toilets are going to be constructed in schools and anganwadi. Quality of rural and urban areas could be improved with proper management of solid and liquid wastes. Some activities like compost pits, vermin composting, recycling of waste water, biogas plants, low cost drainage, soakage channels/ pits segregation and disposal of household garbage etc. will function in this scheme. Information, education and communication activities are also considered as a component under full fledge programme. People are getting aware about the salubrious and clean activities that mobilize the public cognizant. The process of communication is initiated at the very block level in each gram panchayat and village to strength the process of general awareness for this Swachhata Doot are appointed to initiate, direct and monitor. 
TABLE I ACHIEVEMENTS OF SWACHHA BHARAT MisSiON

\begin{tabular}{|l|c|c|c|c|c|c|c|}
\hline \multicolumn{1}{|c|}{ Components } & $\mathbf{2 0 1 2 - 1 3}$ & $\mathbf{2 0 1 3 - 1 4}$ & $\mathbf{2 0 1 4 - 1 5}$ & $\mathbf{2 0 1 5 - 1 6}$ & $\mathbf{2 0 1 6 - 1 7} *$ & $\mathbf{2 0 1 7 - 1 8} *$ & $\mathbf{2 0 1 8 - 1 9} *$ \\
\hline IHHL & $45,59,162$ & $49,76,294$ & $58,54,987$ & $97,73,437$ & $2,18,19,965$ & $2,97,92,287$ & $1,86,03,668$ \\
\hline School Toilets & 76,396 & 37,696 & 25,264 & 8,240 & NA & NA & NA \\
\hline Anganwadi toilets & 36,677 & 22,318 & 8,377 & 1,337 & NA & NA & NA \\
\hline \multicolumn{7}{|c|}{ Source: Swachta Status Report 2016-17, * Data as per the website: www.swachabharatmission.gov.in, NA = not available }
\end{tabular}

In 1999, Government of India launched a sanitation program driven by local communities to build functional toilets in every house and make their villages open defecation free. In the rural areas India had only $22 \%$ household had separate toilets which increased to $96.46 \%$ (Approx) in 2018.The number of institutional toilets also experienced an impressive growth.

TABLE II STATE-WiSe IHHL AND InSTITUTIONAL TOILETS CONSTRUCTEd DURING ThreE YeARS

\begin{tabular}{|c|c|c|c|c|c|c|c|c|c|c|c|c|c|}
\hline \multirow[t]{2}{*}{ S. No. } & \multirow[t]{2}{*}{ State } & \multicolumn{3}{|c|}{2012.13} & \multicolumn{3}{|c|}{ 2013.14 } & \multicolumn{3}{|c|}{$2014-15$} & \multicolumn{3}{|c|}{ 2015.16 (upto 29.2-2016) } \\
\hline & & IHHLls & \begin{tabular}{|l} 
School \\
toliet
\end{tabular} & $\begin{array}{l}\text { Anganwadi } \\
\text { toilet }\end{array}$ & IHAls & $\begin{array}{l}\text { School } \\
\text { toilet }\end{array}$ & $\begin{array}{l}\text { Anganwadi } \\
\text { toilet }\end{array}$ & IHFls & $\begin{array}{l}\text { School } \\
\text { toilet }\end{array}$ & $\begin{array}{l}\text { Anganwadi } \\
\text { toilet }\end{array}$ & IHHLls & \begin{tabular}{|l|} 
School \\
toilet
\end{tabular} & $\begin{array}{l}\text { Anganwadi } \\
\text { toilet }\end{array}$ \\
\hline (1) & (2) & (3) & (4) & (5) & (6) & (7) & (8) & (9) & (10) & (11) & (12) & (13) & (14) \\
\hline 1 & ANDHRA PRADESH & 195102 & 2461 & 515 & 138721 & 2148 & 1305 & 213867 & 85 & 0 & 264356 & 917 & 0 \\
\hline 2 & ARUNACHAL PRADESH & 5760 & 0 & 8 & 14433 & 30 & 148 & 12902 & 255 & 223 & 10002 & 102 & 12 \\
\hline 3 & ASSAM & 273240 & 77 & 76 & 160602 & 633 & 195 & 148237 & 68 & 53 & 416828 & 12 & 1 \\
\hline 4 & BIHAR & 796699 & 17009 & 4822 & 161646 & 5076 & 1437 & 165457 & 1046 & 11 & 199993 & 0 & 0 \\
\hline 5 & CHHATTISGARH & 52045 & 1387 & 220 & 67457 & 0 & 18 & 39128 & 0 & 0 & 242113 & 0 & 17 \\
\hline 6 & D\& N HAVELI & 0 & 0 & 0 & 0 & 0 & 0 & 0 & 0 & 0 & 0 & 0 & 0 \\
\hline 7 & GOA & 0 & 0 & 0 & 0 & 0 & 0 & 0 & 0 & 0 & 28657 & 0 & 0 \\
\hline 8 & GUJARAT & 171977 & 4666 & 451 & 155268 & 1114 & 490 & 335762 & 0 & 0 & 470393 & 0 & 1 \\
\hline 9 & HARYANA & 62949 & 148 & 315 & 116426 & 915 & 718 & 107765 & 2019 & 1722 & 102674 & 153 & 146 \\
\hline 10 & HIMACHAL PRADESH & 5183 & 1215 & 1066 & 9170 & 638 & 38 & 54265 & 182 & 5 & 57011 & 272 & 0 \\
\hline 11 & JAMMU \& KASHMIR & 71900 & 2011 & 76 & 70884 & 363 & 4 & 8496 & 12 & 0 & 52566 & 9 & 1 \\
\hline 12 & JHARKHAND & 48500 & 613 & 684 & 76818 & 682 & 163 & 98512 & 1574 & 157 & 225141 & 22 & 0 \\
\hline 13 & KARNATAKA & 296429 & 1758 & 687 & 505697 & 1483 & 1416 & 791687 & 1355 & 1893 & 417613 & 147 & 123 \\
\hline 14 & KERALA & 5674 & 34 & 322 & 39601 & 400 & 77 & 34101 & 299 & 16 & 11269 & 0 & 0 \\
\hline 15 & MADHYA PRADESH & 558189 & 1033 & 804 & 515583 & 59 & 364 & 521739 & 70 & 2 & 914473 & 6 & 1 \\
\hline 16 & MAHARASHTRA & 189306 & 159 & 5800 & 559042 & 20 & 311 & 500897 & 10 & 5 & 596458 & 1 & 0 \\
\hline 17 & MANIPUR & 43917 & 0 & 53 & 35442 & 0 & 0 & 27860 & 0 & 0 & 41062 & 0 & 0 \\
\hline 18 & MEGHALAYA & 14406 & 1603 & 130 & 29012 & 1678 & 158 & 42002 & 2473 & 171 & 30734 & 1530 & 184 \\
\hline 19 & MIZORAM & 4967 & 106 & 219 & 4524 & 689 & 81 & 534 & 35 & 5 & 3266 & 0 & 0 \\
\hline 20 & NAGALAND & 22149 & 28 & 20 & 20102 & 646 & 283 & 0 & 0 & 0 & 16041 & 0 & 0 \\
\hline 21 & ODISHA & 118318 & 1138 & 956 & 33759 & 373 & 45 & 130925 & 771 & 20 & 913101 & 20 & 0 \\
\hline 22 & \begin{tabular}{|l} 
PUDUCHERRY \\
\end{tabular} & 0 & 0 & 0 & 0 & 0 & 0 & 0 & 0 & 0 & 0 & 0 & 0 \\
\hline 23 & PUNJAB & 57421 & 345 & 620 & 3912 & 0 & 162 & 9887 & 0 & 268 & 47192 & 0 & 0 \\
\hline 24 & RAIASTHAN & 252800 & 15511 & 3421 & 266197 & 6730 & 5718 & 653306 & 949 & 738 & 1963164 & 2079 & 439 \\
\hline 25 & SIKKIM & 0 & 0 & 0 & 3443 & 166 & 100 & 3562 & 505 & 36 & 3707 & 405 & 0 \\
\hline 26 & TAMIL NADU & 324216 & 3095 & 2076 & 313402 & 1403 & 904 & 378162 & 4292 & 49 & 624500 & 378 & 0 \\
\hline 27 & TELANGANA & 189177 & 1738 & 1059 & 180682 & 3686 & 1504 & 130725 & 1937 & 207 & 169719 & 19 & 1 \\
\hline 28 & TRIPURA & 7035 & 412 & 2 & 6077 & 65 & 871 & 24869 & 100 & 858 & 43800 & 0 & 53 \\
\hline 29 & UTTAR PRADESH & 134873 & 30 & 80 & 789092 & 30 & 45 & 515427 & 2 & 0 & 569388 & 0 & 0 \\
\hline 30 & UTTARAKHAND & 97815 & 344 & 19 & 91084 & 169 & 21 & 57833 & 31 & 0 & 43618 & 0 & 0 \\
\hline 31 & WEST BENGAL & 559115 & 19475 & 12176 & 608218 & 8500 & 5742 & 847080 & 7194 & 1938 & 1295618 & 2168 & 358 \\
\hline & Total & 4559162 & 76396 & 36677 & 4976294 & 37696 & 22318 & 5854987 & 25264 & 8377 & 9773437 & 8240 & 1337 \\
\hline
\end{tabular}

Source: Ministry of Drinking water and Sanitation

Sanitation is the basic requirement to live a hygienic and healthy life. Open defecation and unhygienic practices incepted many diseases like diarrhoea, cholera, protozoas and even HIV. The water borne and sanitation related diseases are much more serious and harmful. Intensity of poor sanitation can grave key health problems and worsen the socio-economic condition of a socity. With the inception of SBA the central government of India become too much proactive to make India more clean and healthy country with an inclusive approach corresponding to rural and urban areas. This programme is unique in its basic characteristics considering its scope, scale and funding. It has completed almost four years and since then 8,86,27,723 toilets have been constructed. . It is estimated that the cost of the campaign would be Rs.65000 crores over a period of five years. Under the scheme each deserving household will be provided Rs. 12,000 for the construction of toilets. The propeople feature of the campaign with assigning accountability of individuals makes it a participatory and successful mission. The achievements is embarked by the fact that since $2^{\text {nd }}$ October 2014 India has 5,25,706 villages, 4,465 villages under Namami Gange, 530 Districts and 25 
states/UT declared open defecation free in India.The progress under the scheme is tremendously increasing its pace. In 2014, there were only 38.70 percent coverage of ODF in india which has increased to 96.08 percent showing an annual growth of 14.845 percent impressively running towards full fledge coverage. The number of toilets built in different years are graphically represented in the following diagram.

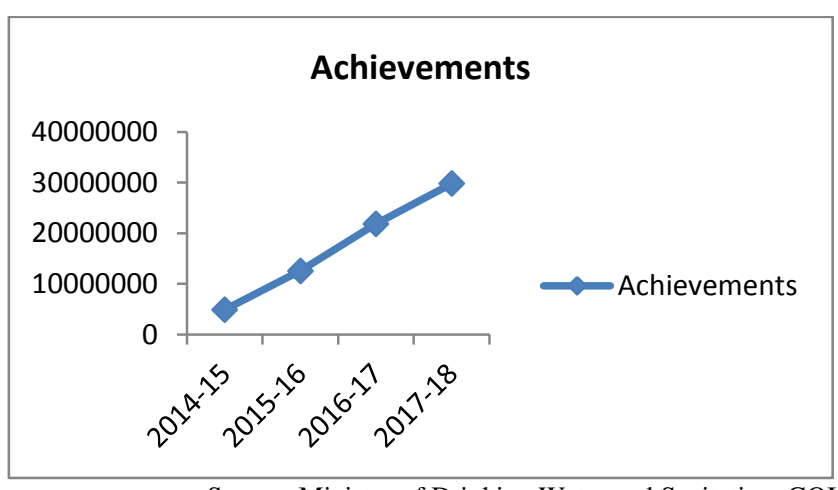

Source: Ministry of Drinking Water and Sanitation, GOI

Fig. 2 Toilets constructed during 2014-18

The number of households toilet constructed in each prescribed year is considered as the parameter of achievement under the scheme. Although, it has shown a gigantic progress in a short span of four years. In 2014-15 the number of toilets constructed was 48,95,932. The scheme worked in a planned manner joining hands with inclusive growth. Progress of toilet built improved by constructing 12559732 in 2015-16, 21820567 in 2016-17 and 29792112 in 2017-18. The Individual Household Latrine (IHHL) constructed under this programme are growing to provide a full coverage throuout the country including states and union territories.

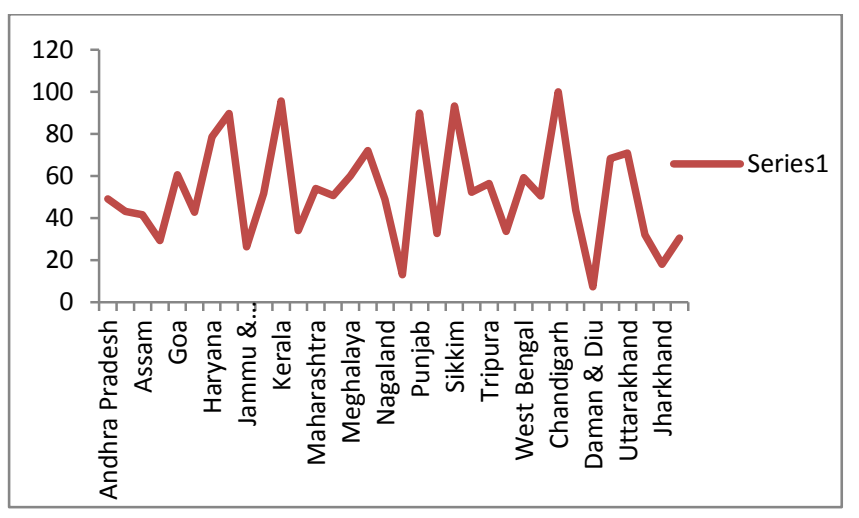

Source: Ministry of Drinking Water and Sanitation, GOI Fig. 3 Percentage coverage of Individual Household Laterine in India2014 (States and Union Terrirories)

\section{A. Economic Impact of Sanitation}

Poor sanitation is an important cause of many other financial, economic and health related losses. It is responsible for creating a huge burden of medical expenses. A study reveals that poor sanitation and unclean water account for the 10 percent global burden of diseases. The water borne diseases can be much more serious than we consider. A study conducted by UNICEF did a cost-benefit analysis of SBM $(G)$ which showed four types of gains such as reduced medical expenses, increased saving, increases longevity and hike in total net worth. According to the report the reduced medical expenses amount to Rs 8024 per household per year which is significantly for a poor country like India. An availability of a concrete toilet reduces the probability of getting ill which later improved the market labour-hours. On an average there is a rise in Rs 24646 per household per year. The financial cost paid by every household on an average account for 16,262 across all households. Out of all the household surveyed $70 \%$ of them fall under the government aid receiving category. The financial incentive to these households averaged Rs. 11800 per household or on an average Rs.8199 per household obtaining latrines and the non-financial cost measured in terms of time of labour is also saved at the rate of wage Rs. 250 per day. The cost and benefit analysis predict that the financial savings exceed the financial costs to the household by 1.7 times on average and for poor households it experienced 2.4 times. Thus the study is highly improving the financial and economic status of the households.

\section{B. Health Impact of Sanitation}

Sanitation is a hygienic habit and its absence can lead to sickness and illness. Most importantly it affects the children as they are more prone to infections and diseases. A report of Ministry of Drinking Water and Sanitation reveals that children belonging to ODF villages would have improved health status than the ones belonging to Non-ODF villages. The findings are as follows:

1. The diarrhoea related deaths are reduced in the ODF villages compared to Non-ODF villages.

2. The height, weight of the children gets affected. One third children are reported as stunted and half of the remaining is moderate in height.

3. Among all the children, one third (34.9\%) were underweight. The proportion of moderately underweight was one-fourth $(21.6 \%)$ while the remaining $(13.9 \%)$ of the underweight children were found to be severely underweight

\section{CONCLUSION}

Sanitation is a practice of keeping the household and surroundings clean and hygienic which keeps the individual disease free. The initiative of PM Modi started in 2014 is impressively progressing towards achieving the targets till the end of 2019. The rate of toilet construction in household and institutions such as schools and anganwadis is getting higher day by day. The Swachta Mission can be called as successful mission of Indian Government in terms of toilet construction, waste management etc. Certain awareness program were initiated by the central government such Swachta Pakhwada to drive the awareness and surveillance programme in universities, ministries and government 
departments. The active engagement of PM makes the programme unique, inclusive and successful.

\section{REFERENCES}

[1] Bertram, J., Lewis, K., Lenton, R. \& Wright, A. (2005). Focussing on improved water and sanitation for health. Elsevier, 365(9461), 810812.

[2] Pal, M. \& Gupta V. (2008). Community Sanitation Campaign: A study in Haryana. Economic Political Weekly. India, 43(33), 20-23.

[3] Joshi, Y., (2018). The Real Status of Real Sanitation. Economic Political Weekly, India, 53(28).

[4] UNICEF Report. (2017). The Financial and Economic Impact of Swachh Bharat Mission in India. Ministry of Drinking Water and Sanitation, India

[5] NSSO Report. (2016). Swachta Status Report. Ministry of Statistics and Programme Implementation, Government of India.

[6] World Bank Report. (2011). Economic impact of inadequate sanitation in India. Water and Sanitation Programme.
[7] SBM Report. (2017). Review of health data in selected ODF and non$O D F$ districts under the SBM. Ministry of Drinking Water and Sanitation, India.

[8] Rao, M G and Singh. (2003). The political economy of center-state physical transfer an India, World Bank, September issue, 1-21.

[9] Isunju, J.B., Schwartz, K., Schouten, M.A., Johnso W.P. \& Dijk M. P. V. (2011). Socio-economic aspects of improved sanitation in slums: A review. Public Health, Elsevier, 125, 1-9.

[10] Meenakshi H. (2015, October). Sanitation and Its Impact on Health: A Study in Jorhat, Assam. International Journal of Scientific and Research Publications, 5(10).

[11] Ohwo, O. \& Agusomu, T. D. (2018). Assessment of Water, Sanitation and Hygiene Services in Sub-Saharan Africa. European Scientific Journal, 14(35), December 2018 edition.

[12] Swain P. \& Pathela S. (2016). Status of sanitation and hygiene practices in the context of "Swachh Bharat Abhiyan" in two districts of India. International Journal of Community Health and Public Medicine, 3(11). 